\title{
Tratamento Medicamentoso
}

Coordenador:

Osvaldo Kohlmann Jr. (SP)

\section{Secretário: \\ Miguel Gus (RS)}

\section{Participantes:}

Artur Beltrame Ribeiro (SP)

Denizar Vianna (RJ)

Eduardo B. Coelho (SP)

Eduardo Barbosa (RS)

Fernando Antonio

Almeida (SP)

Gilson Feitosa (BA)

Heitor Moreno (SP)

Jorge Ilha Guimarães (RS)

$-\mathrm{SBC}$

Jorge Pinto Ribeiro (RS)

José Antonio Franchini

Ramirez (SP)

José Fernando Vilela

Martins (SP)

Robson Augusto S. dos

Santos (MG)

\section{Objetivos}

O objetivo primordial do tratamento da hipertensão arterial é a redução da morbidade e da mortalidade cardiovasculares. ${ }^{1,2}$ Assim, os anti-hipertensivos devem não só reduzir a pressão arterial, mas também os eventos cardiovasculares fatais e não fatais, e, se possível, a taxa de mortalidade. As evidências provenientes de estudos de desfechos clinicamente relevantes, com duração relativamente curta, de três a quatro anos, demonstram redução de morbidade e mortalidade em estudos com diuréticos ${ }^{3-6}$ (A), betabloqueadores $^{3,4,7,8}(\mathrm{~A})$, inibidores da enzima conversora $\mathrm{da}$ angiotensina (IECA) $)^{6,9-13}$ (A), bloqueadores do receptor $\mathrm{AT}_{1}$ da angiotensina (BRA II) ${ }^{14-20}$ (A) e antago-

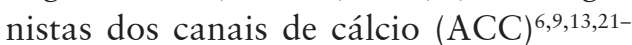
25 (A), embora a maioria dos estudos utilizem, no final, associação de antihipertensivos. Esse benefício é observado com a redução da pressão arterial per se e, com base nos estudos disponíveis até o momento, parece independer da classe de medicamentos utilizados. ${ }^{26}$ Metanálises recentes indicam que esse benefício é de menor monta com betabloqueadores, em especial com atenolol, quando em comparação com os demais anti-hipertensivos. ${ }^{27-29}$

\section{Princípios Gerais do Tratamento Medicamentoso}

Os aspectos importantes na escolha do anti-hipertensivo estão na Tabela 1 . Deve-se explicar, detalhadamente, aos pacientes a ocorrência de possíveis efeitos adversos, a possibilidade de eventuais modificações na terapêutica instituída e o tempo necessário para que o efeito pleno dos medicamentos seja obtido.

\section{Escolha do Medicamento}

Qualquer medicamento dos grupos de anti-hipertensivos (Tabela 2) comercialmente disponíveis, desde que resguardadas as indicações e contraindicações específicas, pode ser utilizado para o tratamento da hipertensão arterial.

Os anti-hipertensivos comercialmente disponíveis no Brasil, por classes, estão mostrados na Tabela 3, enquanto as principais associações medicamentosas podem ser observadas na Tabela 4 .

\section{DIURÉTICOS}

O mecanismo de ação anti-hipertensiva dos diuréticos se relaciona inicialmente aos seus efeitos diuréticos e natriuréticos, com diminuição do volume extracelular. Posteriormente, após cerca de quatro a seis semanas, o volume circulante praticamente se normaliza e há redução da resistência vascular periférica. São eficazes no tratamento da hipertensão arterial, tendo sido comprovada sua eficácia na redução da morbidade e da mortalidade cardiovasculares $^{3-6}$ (A). Para uso como anti-hipertensivos, são preferidos os diuréticos tiazídicos e similares, em baixas doses. Os diuréticos de alça são reservados para situações de hipertensão associada a insuficiência renal com taxa de filtração glomerular abaixo de $30 \mathrm{~mL} / \mathrm{min} / 1,73 \mathrm{~m}^{2}$ (D) e na insuficiência cardíaca com retenção de volume. Em pacientes com aumento do volume extracelular (insuficiências cardíaca e renal), o uso associado de diurético de alça e tiazídico pode ser benéfico tanto para o controle do edema quanto da pressão arterial, ressalvando-se o risco maior de eventos adversos. Os diuréticos poupadores de potássio apresentam pequena eficácia diurética, mas, quando 


\section{Tabela 1 CARACTERÍSTICAS IMPORTANTES DO ANTI-HIPERTENSIVO}

Ser eficaz por via oral

Permitir a administração em menor número possível de tomadas, com preferência para dose única diária

Não ser obtido por meio de manipulação, pela inexistência de informações adequadas de controle de qualidade, bioequivalência e/ou de interação química dos compostos

Ser utilizado por um período mínimo de quatro semanas, salvo em situações especiais, para aumento de dose, substituição da monoterapia ou mudança das associações em uso
Ser seguro e bem tolerado e com relação de risco/ benefício favorável ao paciente

Ser iniciado com as menores doses efetivas preconizadas para cada situação clínica, podendo ser aumentadas gradativamente ressalvando-se que, quanto maior a dose, maiores serão as probabilidades de efeitos adversos

Ser considerado em associação para os pacientes com hipertensão em estágios 2 e 3 e para pacientes de alto e muito alto risco cardiovascular que, na maioria das vezes, não alcançam a meta de redução da pressão arterial preconizada com a monoterapia

Ter demonstração, em ensaios clínicos, da capacidade de reduzir a morbidade e a mortalidade cardiovasculares associadas à hipertensão arterial (característica para preferência de escolha)

\section{Tabela 2 CLASSES DE ANTI-HIPERTENSIVOS} DISPONIVEIS PARA USO CLÍNICO

\section{Diuréticos}

Inibidores adrenérgicos

Ação central - agonistas alfa-2 centrais

Betabloqueadores - bloqueadores beta-adrenérgicos

Alfabloqueadores - bloqueadores alfa-1 adrenérgicos

Vasodilatadores diretos

Bloqueadores dos canais de cálcio

Inibidores da enzima conversora da angiotensina

Bloqueadores do receptor $A T_{1}$ da angiotensina II

Inibidor direto da renina

associados aos tiazídicos e aos diuréticos de alça, são úteis na prevenção e no tratamento de hipopotassemia. Seu uso em pacientes com redução da função renal poderá acarretar hiperpotassemia.

\section{Principais reações adversas}

Hipopotassemia, por vezes acompanhada de hipomagnesemia, que pode induzir arritmias ventriculares, e hiperuricemia. O emprego de baixas doses diminui o risco de efeitos adversos, sem prejuízo da eficácia anti-hipertensiva, especialmente quando em associação com outros anti-hipertensivos. Os diuréticos também podem provocar intolerância à glicose, aumentar o risco do aparecimento do diabetes melito, além de promover aumento de triglicérides, efeitos esses, em geral, dependentes da dose.

\section{INIBIDORES ADRENÉRGICOS}

\section{AÇÃo CENTRAL}

Atuam estimulando os receptores alfa-2 adrenérgicos pré-sinápticos no sistema nervoso central, reduzindo o tônus simpático, como fazem a alfametildopa, a clonidina e o guanabenzo e/ou os inibidores dos receptores imidazolidínicos, como a moxonidina e a rilmenidina.

Seu efeito hipotensor como monoterapia é, em geral, discreto (B). Entretanto, podem ser úteis em associação com medicamentos de outros grupos, particularmente quando há evidência de hiperatividade simpática.

A experiência favorável em relação à segurança do binômio maternofetal recomenda a alfametildopa como agente de escolha para tratamento da hipertensão das grávidas.

Não interferem com a resistência periférica à insulina ou com o perfil lipídico.

\section{Principais reações adversas}

São, em geral, decorrentes da ação central, como sonolência, sedação, boca seca, fadiga, hipotensão postural e disfunção sexual. A frequência é um pouco menor com os inibidores de receptores imidazolidínicos.

A alfametildopa pode provocar, ainda, embora com pequena frequência, galactorreia, anemia hemolítica e lesão hepática, sendo contraindicada se há insuficiência hepática.

No caso da clonidina, destaca-se a hipertensão de rebote, quando da suspensão brusca da medicação, e a ocorrência mais acentuada de boca seca.

\section{BetabloqueAdores}

Seu mecanismo anti-hipertensivo envolve diminuição inicial do débito cardíaco, redução da secreção de renina, readaptação dos barorreceptores e diminuição das catecolaminas nas sinapses nervosas. Betabloqueadores de geração mais recente (terceira geração) como o carvedilol e o nebivolol, diferentemente dos betabloqueadores de primeira e segunda gerações 
Tabela 3 ANTI-HIPERTENSIVOS COMERCIALMENTE DISPONIVEIS NO BRASIL

\begin{tabular}{|c|c|c|c|}
\hline \multirow{2}{*}{ Medicamentos } & \multicolumn{2}{|c|}{ Posologia (mg) } & \multirow{2}{*}{$\begin{array}{l}\text { Número de } \\
\text { tomadas/dia }\end{array}$} \\
\hline & Mínima & Máxima & \\
\hline \multicolumn{4}{|l|}{ Diuréticos } \\
\hline Clortalidona & 12,5 & 25 & 1 \\
\hline Hidroclorotiazida & 12,5 & 25 & 1 \\
\hline Indapamida & 2,5 & 5 & 1 \\
\hline $\begin{array}{l}\text { Indapamida SR*** } \\
\text { Alça }\end{array}$ & 1,5 & 5 & 1 \\
\hline Bumetamida & 0,5 & ** & $1-2$ \\
\hline Furosemida & 20 & ** & $1-2$ \\
\hline Piretanida & 6 & 12 & 1 \\
\hline \multicolumn{4}{|l|}{ Poupadores de potássio } \\
\hline Amilorida* & 2,5 & 10 & 1 \\
\hline Espironolactona & 25 & 100 & $1-2$ \\
\hline Triantereno* & 50 & 100 & 1 \\
\hline \multicolumn{4}{|l|}{ Inibidores adrenérgicos } \\
\hline Alfametildopa & 500 & 1.500 & $2-3$ \\
\hline Clonidina & 0,2 & 0,6 & $2-3$ \\
\hline Guanabenzo & 4 & 12 & $2-3$ \\
\hline Moxonidina & 0,2 & 0,6 & 1 \\
\hline Rilmenidina & 1 & 2 & 1 \\
\hline $\begin{array}{l}\text { Reserpina* } \\
\text { Betabloqueadores }\end{array}$ & 12,5 & 25 & $1-2$ \\
\hline Atenolol & 25 & 100 & $1-2$ \\
\hline Bisoprolol & 2,5 & 10 & $1-2$ \\
\hline Carvedilol $^{+}$ & 12,5 & 50 & $1-2$ \\
\hline Metoprolol e Metoprolol (ZOK)*** & 50 & 200 & $1-2$ \\
\hline Nadolol & 40 & 120 & 1 \\
\hline Nebivolol $^{++}$ & 5 & 10 & 1 \\
\hline Propranolol ${ }^{* *} /$ Propranolol $(\mathrm{LA})^{* * *}$ & $40 / 80$ & $240 / 160$ & $2-3 / 1-2$ \\
\hline $\begin{array}{l}\text { Pindolol } \\
\text { Alfabloqueadores }\end{array}$ & 10 & 40 & $1-2$ \\
\hline Doxazosina & 1 & 16 & 1 \\
\hline Prazosina & 1 & 20 & $2-3$ \\
\hline Prazosina $\mathrm{XL}^{* * *}$ & 4 & 8 & 1 \\
\hline Terazosina & 1 & 20 & $1-2$ \\
\hline Vasodilatadores diretos & & & \\
\hline Hidralazina & 50 & 150 & $2-3$ \\
\hline Minoxidil & 2,5 & 80 & $2-3$ \\
\hline $\begin{array}{l}\text { Bloqueadores dos canais de cál } \\
\text { Fenilalquilaminas }\end{array}$ & & & \\
\hline Verapamil Retard*** & 120 & 480 & $1-2$ \\
\hline Benzotiazepinas & & & \\
\hline Diltiazem AP, SR ou CD*** & 180 & 480 & $1-2$ \\
\hline Diidropiridinas & & & \\
\hline Anlodipino & 2,5 & 10 & 1 \\
\hline Felodipino & 5 & 20 & $1-2$ \\
\hline Isradipina & 2,5 & 20 & 2 \\
\hline Lacidipina & 2 & 8 & 1 \\
\hline Lercarnidipino & 10 & 30 & 1 \\
\hline Manidipino & 10 & 20 & 1 \\
\hline Nifedipino Oros*** & 30 & 60 & 1 \\
\hline Nifedipino Retard*** & 20 & 60 & $2-3$ \\
\hline Nisoldipino & 5 & 40 & $1-2$ \\
\hline Nitrendipino & 10 & 40 & $2-3$ \\
\hline Inibidores da ECA & & & \\
\hline Benazepril & 5 & 20 & 1 \\
\hline Captopril & 25 & 150 & $2-3$ \\
\hline Cilazapril & 2,5 & 5 & 1 \\
\hline Delapril & 15 & 30 & $1-2$ \\
\hline Enalapril & 5 & 40 & $1-2$ \\
\hline Fosinopril & 10 & 20 & 1 \\
\hline Lisinopril & 5 & 20 & 1 \\
\hline Perindopril & 4 & 8 & 1 \\
\hline Quinapril & 10 & 20 & 1 \\
\hline Ramipril & 2,5 & 10 & 1 \\
\hline Trandolapril & 2 & 4 & 1 \\
\hline Bloqueadores do receptor $\mathrm{AT}_{1}$ & & & \\
\hline Candesartana & 8 & 32 & 1 \\
\hline Irbersartana & 150 & 300 & 1 \\
\hline Losartana & 25 & 100 & 1 \\
\hline Olmesartana & 20 & 40 & 1 \\
\hline Telmisartana & 40 & 160 & 1 \\
\hline Valsartana & 80 & 320 & 1 \\
\hline Inibidor direto da renina & & & \\
\hline Alisquireno & 150 & 300 & 1 \\
\hline
\end{tabular}

* Medicamentos comercializados apenas em associaçōes com outros anti-hipertensivos. ** Dose máxima variável de acordo com a indicação médica. *** Retard, SR, ZOK, Oros, XL, LA, AP, SR e CD: formas farmacêuticas de liberaçâo prolongada ou controlada.+ Alfa-1 e betabloqueador adrenérgico. ++ Betabloqueador e liberador de óxido nítrico.
Tabela 4 COMBINAÇÕES FIXAS DE ANTIHIPERTENSIVOS DISPONÍVEIS NO BRASIL

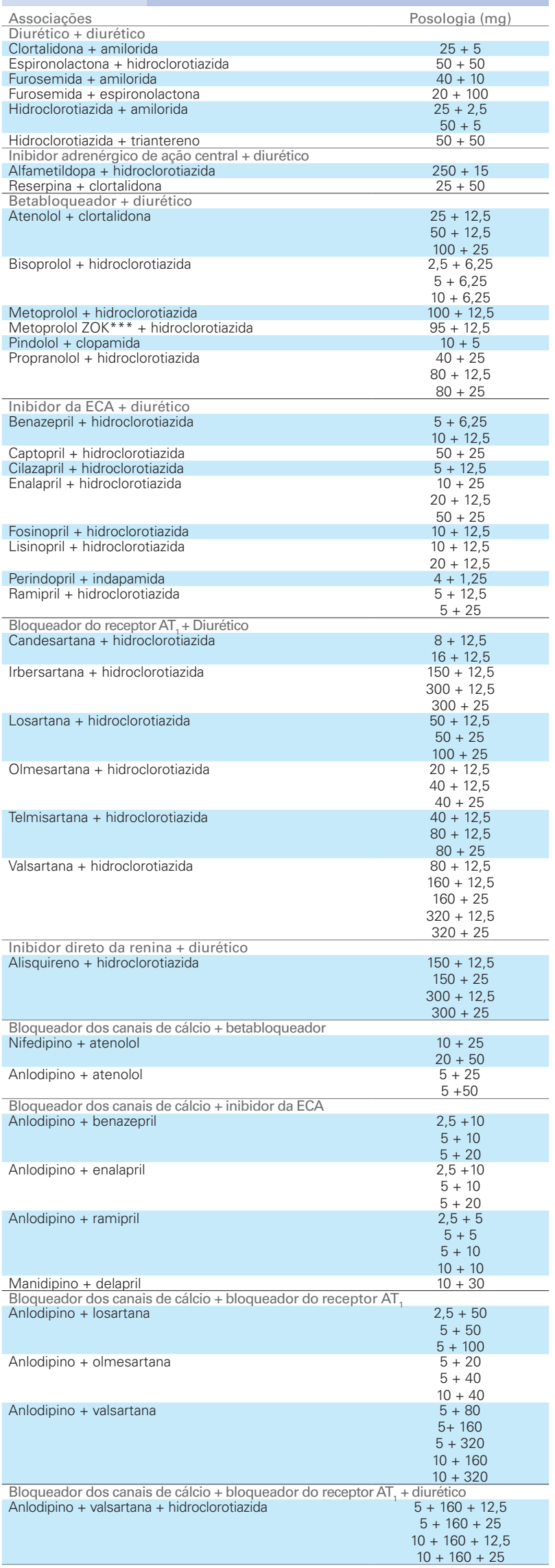


também proporcionam vasodilatação, que no caso do carvedilol decorre em grande parte do efeito de bloqueio concomitante do receptor alfa-1 adrenérgi$\mathrm{co}^{30,31} \mathrm{e}$, no caso do nebivolol, de aumento da síntese e liberação endotelial de óxido nítrico. ${ }^{30,32}$

São eficazes no tratamento da hipertensão arterial. A redução da morbidade e da mortalidade cardiovasculares é bem documentada em grupos de pacientes com idade inferior a $60 \operatorname{anos}^{3,4,7,8}$ (A). Estudos e metanálises recentes ${ }^{27-29}$ não têm apontado redução de desfechos relevantes, principalmente acidente vascular encefálico, em pacientes com idade superior a 60 anos, situação em que o uso dessa classe de medicamentos seria reservada para casos especiais, como nos portadores de coronariopatia, com disfunção sistólica, arritmias cardíacas ou infarto do miocárdio prévio ${ }^{33}$ (A). Estudos de desfecho com carvedilol, metoprolol, bisoprolol e, recentemente, com nebivolol têm demonstrado que esses fármacos são úteis na redução de mortalidade e morbidade cardiovasculares de pacientes com insuficiência cardíaca, hipertensos ou não, independentemente da faixa etária. ${ }^{34-37} \mathrm{O}$ propranolol se mostra também útil em pacientes com tremor essencial, síndromes hipercinéticas, cefaleia de origem vascular e naqueles com hipertensão portal.

\section{Principais reações adversas}

Broncoespasmo, bradicardia, distúrbios da condução atrioventricular, vasoconstrição periférica, insônia, pesadelos, depressão psíquica, astenia e disfunção sexual.

Betabloqueadores de primeira e segunda geração podem acarretar também intolerância à glicose, induzir ao aparecimento de novos casos de diabetes, hipertrigliceridemia com elevação do LDL-colesterol e redução da fração HDL-colesterol. O impacto sobre o metabolismo da glicose é potencializado quando os betabloqueadores são utilizados em combinação com diuréticos. O efeito sobre o metabolismo lipídico parece estar relacionado à dose e à seletividade, sendo de pequena monta com o uso de baixas doses de betabloqueadores cardiosseletivos.

Diferentemente, betabloqueadores de terceira geração, como o carvedilol e o nebivolol, têm impacto neutro ou até podem melhorar o metabolismo da glicose e lipídico, possivelmente em decorrência do efeito de vasodilatação com diminuição da resistência à insulina e melhora da captação de glicose pelos tecidos periféricos. ${ }^{38}$ Estudos com o nebivolol também têm apontado para uma menor interferência na função sexual, ${ }^{39}$ possivelmente em decorrência do efeito sobre a síntese de óxido nítrico endotelial.
A suspensão brusca dos betabloqueadores pode provocar hiperatividade simpática, com hipertensão de rebote e/ou manifestações de isquemia miocárdica, sobretudo em hipertensos com pressão arterial prévia muito elevada. Devem ser utilizados com cautela em pacientes com doença vascular de extremidade.

Os betabloqueadores de primeira e segunda geração são formalmente contraindicados a pacientes com asma brônquica, DPOC e bloqueio atrioventricular de segundo e terceiro graus.

\section{Alfabloqueadores}

Apresentam efeito hipotensor discreto a longo prazo como monoterapia, devendo, portanto, ser associados com outros anti-hipertensivos. Podem induzir ao aparecimento de tolerância, o que exige o uso de doses gradativamente crescentes. Têm a vantagem de propiciar melhora discreta no metabolismo lipídico e glicídico e nos sintomas de pacientes com hipertrofia prostática benigna.

\section{Principais reações adversas}

Hipotensão postural, mais evidente com a primeira dose, sobretudo se a dose inicial for alta, palpitações e, eventualmente, astenia. No estudo ALLHAT, a comparação entre o alfabloqueador doxazosina e a clortalidona indicou a maior ocorrência de insuficiência cardíaca congestiva no grupo tratado com a doxazosina. A partir dessas conclusões estabeleceu-se a ideia de que o alfabloqueador testado nesse estudo não deve ser medicamento de primeira escolha para o tratamento da hipertensão ${ }^{40}(\mathrm{~A})$.

\section{VASODILATADORES DIRETOS}

Atuam sobre a musculatura da parede vascular, promovendo relaxamento muscular com consequente vasodilatação e redução da resistência vascular periférica. São utilizados em associação com diuréticos e/ou betabloqueadores. Hidralazina e minoxidil são dois dos principais representantes desse grupo.

\section{Principais reações adversas}

Pela vasodilatação arterial direta, promovem retenção hídrica e taquicardia reflexa, o que contraindica seu uso como monoterapia.

\section{AntAgONISTAS dos CANAIS DE CÁlCIO}

A ação anti-hipertensiva decorre da redução da resistência vascular periférica por diminuição da concentração de cálcio nas células musculares lisas vasculares. Apesar do mecanismo final comum, esse grupo é dividido em três subgrupos, com características 
químicas e farmacológicas diferentes: fenilalquilaminas, benzotiazepinas e diidropiridinas.

São anti-hipertensivos eficazes e reduzem a morbidade e mortalidade cardiovasculares ${ }^{6,9,13,21-25}$ (A). Deve-se dar preferência aos bloqueadores dos canais de cálcio de longa duração de ação intrínseca ou por formulação galênica que permita uma liberação controlada. Estudo de desfecho reafirmou a eficácia, tolerabilidade e segurança do uso dessa classe de medicamentos no tratamento da hipertensão arterial de pacientes com doença coronariana. ${ }^{41}$ Não são recomendados agentes de curta duração.

\section{Principais reações adversas}

Cefaleia, tontura, rubor facial - mais frequente com diidropiridínicos de curta ação - e edema de extremidades, sobretudo maleolar. Esses efeitos adversos são, em geral, dose-dependentes. Mais raramente, podem induzir a hipertrofia gengival. Os diidropiridínicos de ação curta provocam importante estimulação simpática reflexa, sabidamente deletéria para o sistema cardiovascular. Verapamil e diltiazem podem provocar depressão miocárdica e bloqueio atrioventricular. Obstipação intestinal é observada, particularmente, com verapamil.

\section{INIBIDORES DA ENZIMA CONVERSORA DA ANGIOTENSINA}

Agem fundamentalmente pela inibição da enzima conversora da angiotensina (ECA), bloqueando a transformação da angiotensina I em II no sangue e nos tecidos, embora outros fatores possam estar envolvidos nesse mecanismo de ação. São eficazes no tratamento da HAS, reduzindo a morbidade e a mortalidade cardiovasculares nos hipertensos ${ }^{6,7,10,13,42}(\mathrm{~A})$, pacientes com insuficiência cardíaca ${ }^{43-45}$ (A), com infarto agudo do miocárdio, em especial quando apresentam baixa fração de ejeção ${ }^{11,45-47}(\mathrm{~A})$, de alto risco para doença aterosclerótica ${ }^{11}(\mathrm{~A})$, sendo também úteis na prevenção secundária do acidente vascular encefálico ${ }^{12}(\mathrm{~A})$. Quando administrados a longo prazo, os IECAs retardam o declínio da função renal em pacientes com nefropatia diabética ou de outras etiologias ${ }^{48-50}(\mathrm{~A})$.

\section{Principais reações adversas}

Tosse seca, alteração do paladar e, mais raramente, reações de hipersensibilidade com erupção cutânea e edema angioneurótico.

Em indivíduos com insuficiência renal crônica, podem eventualmente agravar a hiperpotassemia. Em pacientes com hipertensão renovascular bilateral ou unilateral associada a rim único, podem promover redução da filtração glomerular com aumento dos níveis séricos de ureia e creatinina.

Seu uso em pacientes com função renal reduzida pode causar aumento de até $30 \%$ da creatininemia, mas a longo prazo prepondera seu efeito nefroprotetor ${ }^{51}$.

Seu uso é contraindicado na gravidez pelo risco de complicações fetais. Desta forma, seu emprego deve ser cauteloso e frequentemente monitorado em adolescentes e mulheres em idade fértil.

\section{Bloqueadores dos receptores AT, dA ANGIOTEN- SINA II}

Bloqueadores dos receptores $\mathrm{AT}_{1}$ da angiotensina II (BRA II) antagonizam a ação da angiotensina II por meio do bloqueio específico de seus receptores $\mathrm{AT}_{1}$. São eficazes no tratamento da hipertensão. No tratamento da hipertensão arterial, especialmente em populações de alto risco cardiovascular ou com comorbidades, proporcionam redução da morbidade e mortalidade cardiovascular ${ }^{14-20}$ (A). Estudos também comprovam seu efeito benéfico em insuficiência cardíaca congestiva ${ }^{52-54}(\mathrm{~A})$, e são úteis na prevenção do acidente vascular cerebral ${ }^{14,15,55,56}$ (A). São nefroprotetores no paciente com diabetes melito tipo 2 com nefropatia estabelecida ${ }^{57-59}$ (A) e incipiente ${ }^{60}$ (A). Metanálise recente aponta equivalência entre BRA II e IECA na redução de eventos coronarianos ${ }^{61}$ e superioridade dos BRA II na proteção cerebrovascular ${ }^{61}$ contrapondo-se a metanálises anteriores que indicavam redução de eventos coronarianos apenas com os inibidores da ECA. ${ }^{62,63} \mathrm{O}$ tratamento com BRA II, assim como o uso de IECA, vem sendo associado a uma menor incidência de novos casos de diabetes melito tipo $2^{14,16,18,64,65}(\mathrm{~A})$.

\section{Principais reações adversas}

Os bloqueadores do receptor $\mathrm{AT}_{1}$ apresentam bom perfil de tolerabilidade.

Foram relatadas tontura e, raramente, reação de hipersensibilidade cutânea ("rash"). As precauções para seu uso são semelhantes às descritas para os IECA.

\section{INIBIDORES DIRETOS DA RENINA}

Alisquireno, único representante da classe atualmente disponível para uso clínico, promove uma inibição direta da ação da renina com consequente diminuição da formação de angiotensina II. ${ }^{66,67}$ Há ainda especulação sobre outras ações, como redução da atividade plasmática de renina, ${ }^{67}$ bloqueio de um receptor celular próprio de renina/pró-renina ${ }^{67-69}$ e diminuição da síntese intracelular de angiotensina II. ${ }^{70,71}$ 
Estudos de eficácia anti-hipertensiva comprovam sua capacidade, em monoterapia, de redução da pressão arterial de intensidade semelhante aos demais antihipertensivos. ${ }^{72-74}$ Estudos clínicos de curta duração indicam efeito benéfico na redução de morbidade cardiovascular e renal, hipertrofia de ventrículo esquerdo e proteinúria. ${ }^{75-77}$ São aguardados os resultados de estudos de desfecho com avaliação do impacto desse medicamento na mortalidade e morbidade cardiovascular e renal.

\section{Principais reações adversas}

Apresentam boa tolerabilidade.

"Rash" cutâneo, diarreia (especialmente com doses elevadas, acima de $300 \mathrm{mg} /$ dia), aumento de CPK e tosse são os eventos mais frequentes, porém em geral com incidência inferior a $1 \%$. Seu uso é contraindicado na gravidez.

\section{Esquemas Terapêuticos}

\section{Monoterapia}

A monoterapia pode ser a estratégia anti-hipertensiva inicial para pacientes com hipertensão arterial estágio 1 e com risco cardiovascular baixo a moderado.

O tratamento deve ser individualizado e a escolha inicial do medicamento como monoterapia deve-se basear nos seguintes aspectos:

- capacidade de o agente escolhido reduzir morbidade e mortalidade cardiovasculares;

- perfil de segurança do medicamento;
- mecanismo fisiopatogênico predominante no paciente a ser tratado;

- características individuais;

- doenças associadas;

- condições socioeconômicas.

Com base nesses critérios, as classes de anti-hipertensivos atualmente consideradas preferenciais para o controle da pressão arterial em monoterapia inicial são:

- diuréticos ${ }^{3-6}(\mathrm{~A})$;

- betabloqueadores ${ }^{3,4,7,8}$ (A) (com as ressalvas já apontadas na seção 6.3);

- bloqueadores dos canais de cálcio ${ }^{6,9,13,21-25}(\mathrm{~A})$;

- inibidores da $\mathrm{ECA}^{6,8-13}(\mathrm{~A})$;

- bloqueadores do receptor $\mathrm{AT}_{1}{ }^{14-20}(\mathrm{~A})$.

Alisquireno pode ser considerado uma opção para o tratamento inicial em monoterapia dos pacientes com hipertensão estágio 1 , com risco cardiovascular baixo a moderado, ${ }^{72-74}$ ressalvando-se que até o presente momento não estão disponíveis estudos que demonstrem redução de mortalidade cardiovascular com o seu uso.

A posologia deve ser ajustada até que se consiga redução da pressão arterial pelo menos a um nível inferior a $140 / 90 \mathrm{mmHg}^{1,2,78}$ (A). Se o objetivo terapêutico não for conseguido com a monoterapia inicial, três condutas são possíveis:

- se o resultado for parcial ou nulo, mas sem reação adversa, recomenda-se aumentar a dose do medicamento em uso ou associar anti-hipertensivo de outro grupo terapêutico;

- quando não se obtiver efeito terapêutico na dose máxima preconizada, ou se surgirem

Figura 1. Fluxograma para o tratamento da hipertensão arterial.

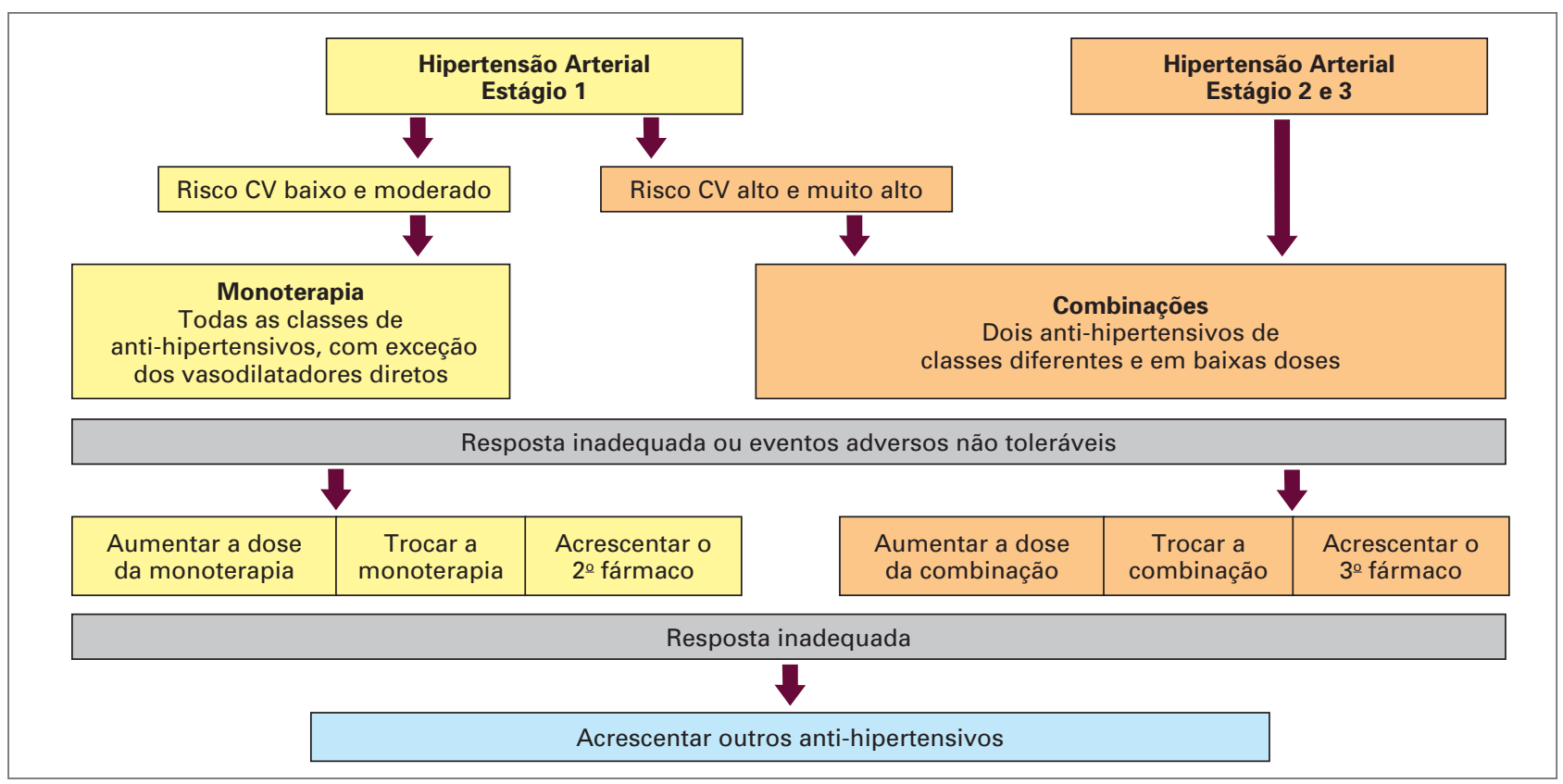


eventos adversos não toleráveis, recomenda-se a substituição do anti-hipertensivo inicialmente utilizado;

- se, ainda assim, a resposta for inadequada, devem-se associar dois ou mais medicamentos (Figura 1).

\section{TERAPÊUTICA ANTI-HIPERTENSIVA COMBINADA}

Com base em evidências de vários estudos mostrando que em cerca de $2 / 3$ dos casos a monoterapia não foi suficiente para atingir as reduções de pressão previstas, e diante da demonstração de que valores da pressão arterial mais baixos $(130 / 80 \mathrm{mmHg})$ podem ser benéficos para pacientes com características peculiares:

- de alto e muito alto risco cardiovascular ${ }^{14,16,78,79}$ (A);

- diabéticos ${ }^{15,79-81}(\mathrm{~A})$;

- com doença renal crônica, ${ }^{57-59,82}$ mesmo que em fase incipiente ${ }^{60}(\mathrm{~A})$;

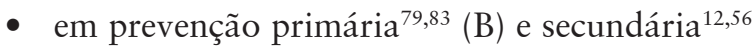
(A) de acidente vascular encefálico, há clara tendência atual para a introdução mais precoce de terapêutica combinada de anti-hipertensivos, como primeira medida medicamentosa, sobretudo nos pacientes com hipertensão em estágios 2 e 3 e para aqueles com hipertensão arterial estágio 1 , mas com risco cardiovascular alto e muito alto.

As associações de anti-hipertensivos (Tabela 5) devem seguir a lógica de não combinar medicamentos com mecanismos de ação similares, com exceção da combinação de diuréticos tiazídicos e de alça com poupadores de potássio. Tais associações de anti-hipertensivos podem ser feitas por meio de medicamentos em separado ou por associações em doses fixas. A eficácia

\section{Tabela 5 AsSOCIAÇÕES RECONHECIDAS COMO EFICAZES}

Diuréticos com outros diuréticos de diferentes mecanismos de ação

Diuréticos com simpatolíticos de ação central

Diuréticos com betabloqueadores

Diuréticos com inibidores da ECA

Diuréticos com bloqueadores do receptor $\mathrm{AT}_{1}$ da angiotensina II

Diuréticos com inibidor direto da renina Diuréticos com bloqueadores dos canais de cálcio

Bloqueadores dos canais de cálcio com betabloqueadores

Bloqueadores dos canais de cálcio com inibidores da ECA

Bloqueadores dos canais de cálcio com bloqueadores do receptor $A T_{1}$

Bloqueadores dos canais de cálcio com inibidor da renina anti-hipertensiva dessas diferentes associações parece ser semelhante, embora sejam escassos os estudos que avaliaram de forma comparativa direta o tratamento com cada uma destas combinações.

Recentemente um estudo de desfechos relevantes avaliou de forma comparativa, em pacientes de alto risco cardiovascular, o impacto do tratamento com a combinação fixa de um IECA com um diurético e com um bloqueador dos canais de cálcio (BCC), tendo sido demonstrado que para o mesmo grau de redução de controle da pressão arterial a combinação do IECA com o BCC foi mais eficaz em reduzir a morbidade e mortalidade cardiovasculares ${ }^{84}$ e a progressão da doença renal..$^{85} \mathrm{O}$ emprego da combinação de betabloqueadores e diuréticos deve ser cauteloso em pacientes com, ou altamente predispostos a apresentar, distúrbios metabólicos, especialmente glicídicos.

$\mathrm{O}$ uso da combinação de inibidor da ECA e bloqueador do receptor $\mathrm{AT}_{1}$ da angiotensina II em pacientes hipertensos, além de não adicionar benefício cardiovascular em comparação com os medicamentos usados em separado, aumentou o risco de eventos adversos $^{20}$, não estando, portanto indicado o seu uso. Exceção se faz em relação àqueles com insuficiência cardíaca classes 3 e 4 da NYHA ${ }^{52,53}$ ou com proteinúria $^{86,87}$ e, mesmo assim, devem ser usados com cautela.

Algumas associações destacadas na Tabela 4 também estão disponíveis no mercado em doses fixas. Seu emprego, desde que criterioso, pode ser útil por simplificar o esquema posológico, reduzindo o número de comprimidos administrados e, assim, estimulando a adesão ao tratamento. Se o objetivo terapêutico não for conseguido com a combinação inicial, três condutas são possíveis:

- se o resultado for parcial ou nulo, mas sem reação adversa, recomenda-se aumentar a dose da combinação em uso ou associar um terceiro anti-hipertensivo de outra classe;

- quando não se obtiver efeito terapêutico na dose máxima preconizada, ou se surgirem eventos adversos não toleráveis, recomenda-se a substituição da combinação;

- se ainda assim a resposta for inadequada, devem-se associar outros anti-hipertensivos (Figura 1).

Quando já estão sendo usados pelo menos dois medicamentos, o uso de um diurético é fundamental.

Pacientes aderentes ao tratamento e não responsivos à tríplice terapia otimizada que inclua um diurético caracterizam a situação clínica de hipertensão resistente. Nesta situação clínica deverá ser avaliada a presença de fatores que dificultam o controle da 
pressão arterial, tais como ingestão excessiva de sal, álcool, obesidade, uso de fármacos com potencial de elevar a pressão arterial, síndrome de apneia obstrutiva do sono e formas secundárias de hipertensão arterial, procedendo à correção destes fatores. Se ausentes ou se a pressão arterial persistir elevada mesmo após a correção dos fatores de agravamento do quadro hipertensivo, a adição de espironolactona e de simpatolíticos centrais e betabloqueadores ao esquema terapêutico tem-se mostrado útil. ${ }^{88}$ Reserva-se para pacientes que não responderam adequadamente à estratégia proposta a adição de vasodilatadores diretos, como hidralazina e minoxidil, que devem ser usados em combinação com diuréticos e betabloqueadores.

\section{OUTRAS CONSIDERAÇÕES A RESPEITO DA TERAPÊUTICA} ANTI-HIPERTENSIVA

Com relação ao tratamento anti-hipertensivo deve-se também considerar:

- o esquema anti-hipertensivo deve manter a qualidade de vida do paciente, de modo a estimular a adesão às recomendações prescritas;

- existem evidências de que para hipertensos com a pressão arterial controlada a prescrição de ácido acetilsalicílico em baixas doses ( $75 \mathrm{mg}$ ) diminui a ocorrência de complicações cardiovasculares, desde que não haja contraindicação para o seu uso e que os benefícios superem os eventuais riscos da sua administração ${ }^{79,89}(\mathrm{~A})$;

- dada a necessidade de tratamento crônico da hipertensãoarterial, o Sistema Único de Saúde deve garantir o fornecimento contínuo de, pelo menos, um representante decada uma das cinco principais classes de anti-hipertensivos comumente usados.

\section{InTERAções Medicamentosas}

É importante conhecer as principais interações de anti-hipertensivos e medicamentos de uso contínuo que podem ser prescritos para o paciente hipertenso (Tabela 6).

\section{Adesão ao Tratamento}

A adesão ao tratamento é definida como o grau de coincidência entre a prescrição e o comportamento do paciente. Vários são os determinantes para a não adesão ao tratamento ${ }^{90-92}$ (Tabela 7).

Os percentuais de controle de pressão arterial são muito baixos, apesar das evidências de que o tratamento anti-hipertensivo é eficaz em diminuir a morbidade e mortalidade cardiovascular, devido à baixa adesão ao tratamento. Estudos isolados apontam controle de $20 \%$ a $40 \% .{ }^{93,94}$ A taxa de abandono, grau mais elevado de falta de adesão, é crescente conforme o tempo decorrido após o início da terapêutica. A Tabela 8 indica sugestões para melhorar a adesão às prescrições para os hipertensos.

A relação médico/paciente deve ser a base de sustentação para o sucesso do tratamento anti-hipertensivo. A participação de vários profissionais da área da saúde, com uma abordagem multidisciplinar, pode facilitar a adesão ao tratamento anti-hipertensivo e consequentemente aumentar o controle da hipertensão arterial (Tabela 8). ${ }^{95}$

\section{Complicações Hipertensivas Agudas}

Pressão arterial muito elevada, acompanhada de sintomas, caracteriza uma complicação hipertensiva aguda e requer avaliação clínica adequada, incluindo exame físico detalhado, fundoscopia e exames complementares, solicitados para avaliação das lesões em órgãos-alvo.

\section{URGÊNCIAS HIPERTENSIVAS}

A elevação crítica da pressão arterial, em geral pressão arterial diastólica $\geq 120 \mathrm{mmHg}$, porém com estabilidade clínica, sem comprometimento de órgãos-alvo, caracteriza o que se convencionou definir como urgência hipertensiva (UH).

Pacientes que cursam com UH estão expostos a maior risco futuro de eventos cardiovasculares comparados com hipertensos que não a apresentam, fato que evidencia o seu impacto no risco cardiovascular de indivíduos hipertensos e enfatiza a necessidade de controle adequado da pressão arterial cronicamente. ${ }^{96}$ A pressão arterial, nesses casos, deverá ser tratada com medicamentos por via oral buscando-se redução da pressão arterial em até 24 horas (D).

Embora a administração sublingual de nifedipino de ação rápida seja amplamente utilizada para esse fim, foram descritos efeitos adversos graves com essa conduta. A dificuldade de controlar o ritmo e o grau de redução da pressão arterial, sobretudo quando intensa, pode ocasionar acidentes vasculares encefálicos e coronarianos. O risco de importante estimulação simpática secundária e a existência de alternativas eficazes e mais bem toleradas tornam o uso de nifedipino de curta duração (cápsulas) não recomendável nessa situação. O uso desse medicamento, sobretudo de forma abusiva, foi analisado em parecer técnico do Conselho Regional de Medicina do Estado de São Paulo (http:// www.cremesp.org.br) - clicar em pareceres (parecer CREMESP 45922 de 2003). 
Tabela 6 ANTI-HIPERTENSIVOS: INTERAÇÕES MEDICAMENTOSAS

\begin{tabular}{|c|c|c|}
\hline Anti-hipertensivo & Medicamentos & Efeitos \\
\hline \multicolumn{3}{|l|}{ Diuréticos } \\
\hline \multirow[t]{4}{*}{ Tiazídicos e de alça } & Digitálicos & Intoxicação digitálica por hipopotassemia \\
\hline & Anti-inflamatórios esteroides e não esteroides & Antagonismo do efeito diurético \\
\hline & Hipoglicemiantes orais & Efeito diminuído pelos tiazídicos \\
\hline & Lítio & Aumento dos níveis séricos do lítio \\
\hline Poupadores de potássio & Suplementos de potássio e inibidores da ECA & Hipercalemia \\
\hline \multicolumn{3}{|c|}{ Inibidores adrenérgicos } \\
\hline Ação central & Antidepressivos tricíclicos & Redução do efeito anti-hipertensivo \\
\hline \multirow[t]{9}{*}{ Betabloqueadores } & Insulina e hipoglicemiantes orais & $\begin{array}{l}\text { Redução dos sinais de hipoglicemia e bloqueio da } \\
\text { mobilização de glicose }\end{array}$ \\
\hline & Amiodarona quinidina & Bradicardia \\
\hline & Cimetidina & $\begin{array}{l}\text { Redução da depuração hepática de propranolol e } \\
\text { metoprolol }\end{array}$ \\
\hline & Cocaína & Potencialização do efeito da cocaína \\
\hline & Vasoconstritores nasais & $\begin{array}{l}\text { Facilitação do aumento da pressão pelos } \\
\text { vasoconstritores nasais }\end{array}$ \\
\hline & Diltiazem, verapamil & Bradicardia, depressão sinusal e atrioventricular \\
\hline & Dipiridamol & Bradicardia \\
\hline & Anti-inflamatórios esteroides e não esteroides & Antagonismo do efeito hipotensor \\
\hline & $\begin{array}{l}\text { Diltiazem, verapamil, betabloqueadores e } \\
\text { medicamentos de ação central }\end{array}$ & Hipotensão \\
\hline \multicolumn{3}{|l|}{ Inibidores da ECA } \\
\hline & Suplementos e diuréticos poupadores de potássio & Hipercalemia \\
\hline & Ciclosporina & Aumento dos níveis de ciclosporina \\
\hline & Anti-inflamatórios esteroides e não esteroides & Antagonismo do efeito hipotensor \\
\hline & Lítio & Diminuição da depuração do lítio \\
\hline & Antiácidos & Redução da biodisponibilidade do captopril \\
\hline & $\begin{array}{l}\text { Hipoglicemiantes da classe dos inibidores da } \\
\text { enzima DPP4 }\end{array}$ & $\begin{array}{l}\text { Aumento do risco de angioedema associado ao } \\
\text { uso de IECA }\end{array}$ \\
\hline \multicolumn{3}{|c|}{ Bloqueadores dos canais de cálcio } \\
\hline & Digoxina & $\begin{array}{l}\text { Verapamil e diltiazem aumentam os níveis de } \\
\text { digoxina }\end{array}$ \\
\hline & Bloqueadores de $\mathrm{H} 2$ & $\begin{array}{l}\text { Aumento dos níveis dos bloqueadores dos } \\
\text { canais de cálcio }\end{array}$ \\
\hline & Ciclosporina & $\begin{array}{l}\text { Aumento do nível de ciclosporina, com } \\
\text { exceção de anlodipino e felodipino }\end{array}$ \\
\hline & Teofilina, prazosina & Níveis aumentados com verapamil \\
\hline & Moxonidina & Hipotensão \\
\hline \multicolumn{3}{|c|}{ Bloqueadores do receptor $\mathrm{AT}_{1}$} \\
\hline & Moxonidina & Hipotensão com losartana \\
\hline & Suplementos e diuréticos poupadores de potássio & Hipercalemia \\
\hline \multicolumn{3}{|c|}{ Inibidor direto da renina } \\
\hline & Ciclosporina e cetoconazol & $\begin{array}{l}\text { Aumento da concentração plasmática de } \\
\text { alisquireno }\end{array}$ \\
\hline & Furosemida & $\begin{array}{l}\text { Redução da biodisponibilidade da furosemida - } \\
\text { redução do efeito natriurético }\end{array}$ \\
\hline & Suplementos e diuréticos poupadores de potássio & Hipercalemia \\
\hline
\end{tabular}

\section{EMERGÊNCIAS HIPERTENSIVAS}

É condição em que há elevação crítica da pressão arterial com quadro clínico grave, progressiva lesão de órgãos-alvo e risco de morte, exigindo imediata redução da pressão arterial com agentes aplicados por via parenteral (D) (Tabela 9). Há elevação abrupta da pressão arterial ocasionando, em território cerebral, perda da autorregulação do fluxo sanguíneo e evidências de lesão vascular, com quadro clínico de encefalopatia hipertensiva, lesões hemorrágicas dos vasos da retina e papiledema. Habitualmente, apresentam-se com pressão arterial muito elevada em pacientes com hipertensão crônica ou menos elevada em pacientes com doença aguda, como em eclâmpsia, glomerulonefrite aguda, e em uso de drogas ilícitas, como cocaína. Podem estar associadas a acidente vascular encefálico, edema agudo 


\section{Tabela 7 PRINCIPAIS DETERMINANTES DA NÃO ADESÃO AO TRATAMENTO ANTI-HIPERTENSIVO}

Falta de conhecimento por parte do paciente sobre a doença ou de motivação para tratar uma doença assintomática e crônica

Baixo nível socioeconômico, aspectos culturais e crenças erradas adquiridas em experiências com a doença no contexto familiar e baixa auto-estima

Relacionamento inadequado com a equipe de saúde

Tempo de atendimento prolongado, dificuldade na marcação de consultas, falta de contato com os faltosos e com aqueles que deixam o serviço

Custo elevado dos medicamentos e ocorrência de efeitos indesejáveis

Interferência na qualidade de vida após início do tratamento

\section{Tabela 8 PRINCIPAIS SUgESTÕES PARA A MELHOR ADESÃO AO TRATAMENTO ANTI-HIPERTENSIVO}

Educação em saúde com especial enfoque sobre conceitos de hipertensão e suas características

Orientações sobre os benefícios dos tratamentos, incluindo mudanças de estilo de vida

Informações detalhadas e compreensíveis aos pacientes sobre os eventuais efeitos adversos dos medicamentos prescritos e necessidades de ajustes posológicos com o passar do tempo

Cuidados e atenções particularizadas em conformidade com as necessidades

Atendimento médico facilitado sobretudo no que se refere ao agendamento de consultas

\section{Tabela 9 MedicAmENTOS usAdOS POR VIA PARENTERAL PARA O TRATAMENTO DAS EMERGÊNCIAS HIPERTENSIVAS}

\begin{tabular}{|c|c|c|c|c|c|}
\hline Medicamentos & Dose & Início & Duração & $\begin{array}{l}\text { Efeitos adversos } \\
\text { e precauções }\end{array}$ & Indicações \\
\hline $\begin{array}{l}\text { Nitroprussiato de } \\
\text { sódio (vasodilatador } \\
\text { arterial e venoso) }\end{array}$ & $0,25-10 \mathrm{mg} / \mathrm{kg} / \mathrm{min} \mathrm{EV}$ & Imediato & $1-2 \mathrm{~min}$ & $\begin{array}{l}\text { Náuseas, vômitos, } \\
\text { intoxicação por } \\
\text { cianeto. Cuidado na } \\
\text { insuficiência renal e } \\
\text { hepática e na pressão } \\
\text { intracraniana alta. } \\
\text { Hipotensão grave }\end{array}$ & $\begin{array}{l}\text { Maioria das emergências } \\
\text { hipertensivas }\end{array}$ \\
\hline $\begin{array}{l}\text { Nitroglicerina } \\
\text { (vasodilatador } \\
\text { arterial e venoso) }\end{array}$ & 5-100 mg/min EV & $2-5 \min$ & $3-5 \min$ & $\begin{array}{l}\text { Cefaleia, taquicardia } \\
\text { reflexa, taquifilaxia, } \\
\text { flushing, meta- } \\
\text { emoglobinema }\end{array}$ & $\begin{array}{l}\text { Insuficiência coronariana, } \\
\text { insuficiência ventricular } \\
\text { esquerda }\end{array}$ \\
\hline $\begin{array}{l}\text { Hidralazina } \\
\text { (vasodilatador de } \\
\text { ação direta) }\end{array}$ & $\begin{array}{l}10-20 \mathrm{mg} \text { EV ou } \\
10-40 \mathrm{mg} \text { IM 6/6 h }\end{array}$ & 10-30 min & $3-12 h$ & $\begin{array}{l}\text { Taquicardia, cefaleia, } \\
\text { vômitos. Piora da } \\
\text { angina e do infarto. } \\
\text { Cuidado com pressão } \\
\text { intracraniana elevada }\end{array}$ & Eclâmpsia \\
\hline $\begin{array}{l}\text { Metoprolol } \\
\text { (bloqueador } \\
\beta \text {-adrenérgico } \\
\text { seletivo) }\end{array}$ & $\begin{array}{l}5 \text { mg EV (repetir 10/10 } \\
\text { min, se necessário até } \\
20 \text { mg) }\end{array}$ & $5-10 \mathrm{~min}$ & $3-4 h$ & $\begin{array}{l}\text { Bradicardia, bloqueio } \\
\text { atrioventricular } \\
\text { avançado, } \\
\text { insuficiência cardíaca, } \\
\text { broncoespasmo }\end{array}$ & $\begin{array}{l}\text { Insuficiência coronariana. } \\
\text { Dissecção aguda de } \\
\text { aorta (em combinação } \\
\text { com NPS). }\end{array}$ \\
\hline $\begin{array}{l}\text { Esmolol } \\
\text { (bloqueador } \\
\beta \text {-adrenérgico } \\
\text { seletivo } \\
\text { de ação } \\
\text { ultrarrápida) }\end{array}$ & $\begin{array}{l}\text { Ataque: } 500 \mu \mathrm{g} / \mathrm{kg} \\
\text { Infusão intermitente: } \\
25-50 \mu \mathrm{g} / \mathrm{kg} / \mathrm{min} \\
\uparrow 25 \mu \mathrm{g} / \mathrm{kg} / \mathrm{min} \text { cada } \\
10-20 \mathrm{~min} \\
\text { Máximo: } 300 \mu \mathrm{g} / \mathrm{kg} / \mathrm{min}\end{array}$ & $1-2 \mathrm{~min}$ & $1-20 \mathrm{~min}$ & $\begin{array}{l}\text { Náuseas, vômitos, } \\
\text { BAV 1 grau, espasmo } \\
\text { brônquico, hipotensão }\end{array}$ & $\begin{array}{l}\text { Dissecção aguda de } \\
\text { aorta (em combinação } \\
\text { com NPS). Hipertensão } \\
\text { pós-operatória grave }\end{array}$ \\
\hline $\begin{array}{l}\text { Furosemida } \\
\text { (diurético) }\end{array}$ & $\begin{array}{l}20-60 \text { mg (repetir após } \\
30 \text { min) }\end{array}$ & $2-5 \min$ & $\begin{array}{l}30-60 \\
\min \end{array}$ & Hipopotassemia & $\begin{array}{l}\text { Insuficiência ventricular } \\
\text { esquerda. Situações de } \\
\text { hipervolemia }\end{array}$ \\
\hline $\begin{array}{l}\text { Fentolamina } \\
\text { (bloqueador } \\
\beta \text {-adrenérgico) }\end{array}$ & $\begin{array}{l}\text { Infusão contínua: 1-5 mg } \\
\text { Máximo: } 15 \text { mg }\end{array}$ & $1-2 \min$ & $3-5 \min$ & $\begin{array}{l}\text { Taquicardia reflexa, } \\
\text { flushing, tontura, } \\
\text { náuseas, vômitos }\end{array}$ & $\begin{array}{l}\text { Excesso de } \\
\text { catecolaminas }\end{array}$ \\
\hline
\end{tabular}

(NPS: nitroprussiato de sódio) 
dos pulmões, síndromes isquêmicas miocárdicas agudas e dissecção aguda da aorta. Nesses casos, há risco iminente à vida ou de lesão orgânica grave.

Depois de obtida a redução imediata da pressão arterial, deve-se iniciar a terapia anti-hipertensiva de manutenção e interromper a medicação parenteral. A hidralazina é contraindicada nos casos de síndromes isquêmicas miocárdicas agudas e de dissecção aguda de aorta por induzir ativação simpática, com taquicardia e aumento da pressão de pulso. Em tais situações, indica-se o uso de betabloqueadores e de nitroglicerina ou nitroprussiato de sódio (C).

$\mathrm{Na}$ fase aguda de acidente vascular encefálico, a redução da pressão arterial deve ser gradativa e cuidadosa, evitando-se reduções bruscas e excessivas, não havendo consenso para se estabelecer a pressão arterial ideal a ser atingida.

\section{Análise Econômica do Tratamento da HI- pertensão Arterial Sistêmica no Brasil}

A análise de custo-efetividade do tratamento anti-hipertensivo é útil para orientar a alocação de recursos dos financiadores do sistema de saúde, tanto públicos como privados, porém não é capaz de responder as questões específicas sobre o impacto orçamentário. Existem modelos econômicos específicos para análise de impacto no orçamento em que o financiador estima, a partir do número de pessoas beneficiadas e da prevalência da doença em questão, qual será o comprometimento no seu orçamento. Essa análise permite complementar a tomada de decisão sobre o financiamento da terapêutica para HAS.

Dib et al. ${ }^{97}$ utilizaram a prevalência de $28,5 \%$ (33,6 milhões de indivíduos hipertensos no ano de 2005). Os autores levaram em consideração que aproximadamente $50 \%$ dos indivíduos hipertensos não estão diagnosticados ${ }^{98}$ e somente $52 \%$ encontram-se em tratamento medicamentoso [Projeto Corações do Brasil (online). Atlas Corações do Brasil]. ${ }^{99}$

Os grupos de pacientes foram divididos em estágios 1,2 e 3 , com prevalência de $53,3 \%, 35,7 \%$ e $11 \%$ respectivamente. O custo anual para tratamento da HAS no Sistema Único de Saúde foi de aproximadamente R \$ 969.231.436,00 e no Sistema Suplementar de Saúde, de R\$ 662.646.950,00 (Tabela 10). O custo total com o tratamento da HAS representou $0,08 \%$ do produto interno bruto (PIB) Brasileiro em 2005 (Tabela 10).

Para subsidiar políticas de saúde em hipertensão, estudo brasileiro que avaliou taxas de conhecimento e controle da hipertensão arterial e a relação custo-efetividade do tratamento anti-hipertensivo em uma cidade de grande porte do estado de São Paulo mostrou que o uso de betabloqueador em monoterapia proporcionou a melhor taxa de controle da pressão arterial, mas que o uso de diurético foi o mais custo-efetivo. ${ }^{100}$

Tabela 10 ESTIMATIVA dOS RECURSOS UTILIZADOS COM O TRATAMENTO DA HIPERTENSÃO ARTERIAL SISTÊMICA EM 2005

\begin{tabular}{lccccc} 
& SUS (80\%) & \% total & Suplementar (20\%) & \% total & Total (R\$) \\
\hline Consulta médica & $200.349 .916,47$ & $21 \%$ & $278.632 .334,16$ & $42 \%$ & $478.982 .250,63$ \\
Avaliação nutricional & $21.116 .137,91$ & $2 \%$ & $29.366 .814,31$ & $5 \%$ & $50.482 .952,22$ \\
Exames complementares & $160.328 .821,93$ & $17 \%$ & $113.551 .681,99$ & $17 \%$ & $273.880 .503,92$ \\
Medicamentos anti-hipertensivos & $507.754 .332,05$ & $52 \%$ & $181.340 .832,87$ & $27 \%$ & $689.095 .164,92$ \\
Atendimento de urgência & $79.682 .228,48$ & $8 \%$ & $59.755 .287,01$ & $9 \%$ & $139.437 .515,49$ \\
Total & $969.231 .436,83$ & & $662.646 .950,35$ & $1.631 .878 .387,19$ \\
\hline
\end{tabular}

\section{REFERÊNCIAS}

1. Kannel WB. Blood pressure as a cardiovascular risk factor: prevention and treatment. JAMA 1996; 273:1571-1576.

2. Padwal R, Straus SE, McAlister FA. Cardiovascular risk factors and their impact on decision to treat hypertension: an evidence-based review. BMJ 2001; 322:977-980.

3. Psaty BM, Smith NL, Siscovick DS et al. Health outcomes associated with antihypertensive therapies used as firstline agents. A systematic review and metaanalysis. JAMA 1977; 277:739-745.
4. Wright JM, Lee C-H, Chamber GK. Systematic review of antihypertensive therapies: does the evidence assist in choosing a first-line drug. CMAJ 1999;161:25-32.

5. SHEP-Cooperative Research Group. Prevention of stroke by antihypertensive drug treatment in older persons with isolated systolic hypertension: final results of the Systolic Hypertension in the Elderly Program (SHEP). JAMA 1991; 265:3255-3264.

6. The ALLHAT Officers and Coordinators for the ALLHAT Collaborative Research Group. Major outcome in high-risk hypertensive patients to angiotensin-converting enzyme inhibitor or calcium channel blocker $v s$. diuretic. The Antihypertensive and 
Lipid-Lowering Treatment to Prevent Heart Attack Trial (ALLHAT). JAMA 2002; 228:2981-2997.

7. Medical Research Council Working Party. MRC trial of treatment of hypertension: principal results. BMJ 1985; 291:97-104.

8. UK Prospective Diabetes Study Group. Efficacy of atenolol and captopril in reducing risk of macrovascular and microvascular complications in type 2 diabetes. UKPDS 39. BMJ 1998; 317:713-720.

9. Neal B, MacMahon S, Chapman N. Blood Pressure Lowering Trialist's Collaboration. Effects of ACE inhibitors, calcium antagonists and other bloodpressure-lowering drugs: results of prospectively designed overviews of randomized trials. Lancet 2000; 356:1955-1964.

10. Hansson L, Lindholm, Niskanen L et al. Effect of angiotensin converting enzyme inhibition compared with conventional therapy on cardiovascular morbidity and mortality on hypertension: the Captopril Prevention Project (CAPPP) randomized trial. Lancet 1999; 353:611-616.

11. The Heart Outcomes Prevention Evaluation Study Investigators. Effects of an angiotensin converting enzyme inhibitor, ramipril, on cardiovascular events in high-risk patients. N Engl J Med 2000; 342:145-153.

12. PROGRESS Collaborative Group. Randomized trial of a perindopril-based-blood pressure-lowering regimen among 6,105 individuals with previous stroke or transient ischaemic attack. Lancet 2001; 35:1033-1041.

13. Hansson L, Lindholm LH, Ekborn T et al. Randomized trial of old and new antihypertensive drugs in elderly patients: cardiovascular mortality and morbidity. The Swedish Trial in Old Patients with Hypertension-2 study. Lancet 1999; 34:1129-1133.

14. Dahlof B, Devereux R, Kjeldsen S et al. Cardiovascular morbidity and mortality in the losartan intervention or endpoint reduction in hypertension study (LIFE): a randomized trial against atenolol. Lancet 2002; 359:995-1003.

15. Lindholm LH, Ibsen H, Dahlof B et al. Cardiovascular morbidity and mortality in patients with diabetes in the Losartan Intervention For Endpoint reduction in hypertension study (LIFE): a randomized trial against atenolol. Lancet 2002; 359:1004-1010.

16. Julius S, Kejdelsen SE, Weber M, et al. Outcomes in hypertensive patients in high cardiovascular risk treated with regimens based on valsartan and amlodipine: the VALUE radomised trial. Lancet 2004; 363:2022-2031.

17. Julius S, Weber MA, Kjeldsen SE et al. Martinez F, Oigman W, Seabra Gomes R, Zhu JR. The Valsartan Antihypertensive Long-Term Use Evaluation (VALUE) trial: outcomes in patients receiving monotherapy. Hypertension 2006; 48(3):385-391.

18. Ogihara T, Nakao K, Fukui T et al. Effects of candesartan compared with amlodipine in hypertensive patients with high cardiovascular risks. Candesartan Antihypertensive Survival Evaluation in Japan trial (CASE-J). Hypertension 2008; 51:1-6.

19. Suzuki H, Kanno Y. Effects of candesartan on cardiovascular outcomes in Japanese hypertensive patients (E-COST). Hypertens Res 2005; 28:307-314.
20. Telmisartan, Ramipril, or Both in Patients at High Risk for Vascular Events. The ON-TARGET Investigators. N Engl J Med 2008; 358:1547-1559.

21. Stassen JA, Fagard R, Thijs L. Randomized doubleblind comparison of placebo and active treatment for older patients with isolated systolic hypertension. The Systolic hypertension in Europe (SYST-EUR). Lancet 1997; 350:757-764.

22. Brown MJ, Palmer CR, Castaigne A et al. Morbidity and mortality in patients randomized to double-blind treatment with long-acting calcium-channel blocker or diuretic in the International Nifedipine GITS study: Intervention as a Goal in Hypertension Treatment (INSIGHT). Lancet 2000; 356:366-372.

23. Hansson L, Hedner T, Lund-Johansen $\mathrm{P}$ et al. Randomized trial of effects of calcium antagonists compared with diuretics and alpha-blockers on cardiovascular morbidity and mortality in hypertension: the Nordic Diltiazen (NORDIL) study. Lancet 2000; 356:359-365.

24. Pahor M, Psaty BM, Alderman MH et al. Health outcomes associated with calcium antagonists compared with other first-line antihypertensive therapies: a meta-analyses of randomized controlled trials. Lancet 2000; 356:1949-1954.

25. Dahlof B, Sever PS, Poulter NR et al. ASCOT Investigators. Prevention of cardiovascular events with an antihypertensive regimen of amlodipine adding perindopril as required versus atenolol adding bendroflumethiazide as required, in the Anglo-Scandinavian Cardiac Outcomes Trial-Blood Pressure Lowering Arm (ASCOT-BPLA): a multicentre randomised controlled trial. Lancet 2005; 366:895-906.

26. Law MR, Morris JK, Wald NJ. Use of blood pressure lowering drugs in the prevention of cardiovascular disease: meta-analysis of 147 randomised trials in the context of expectations from prospective epidemiological studies. BMJ 2009; 338:b1665.

27. Calberg B, Samuelsson O, Lindholm LH. Atenolol in hypertension: is it a wise choice? Lancet 2004; 364:1684-1689.

28. Lindholm LH, Calberg B, Samuelsson O. Should $\beta$ blocker remain a first choice in the treatment of primary hypertension? A meta-analysis. Lancet 2005: 366:1545-1553.

29. Bradley H, Wiysonge CS, Volmink JA, Mayosi BM, Opie LH. How strong is the evidence for the use of beta-blockers as first-line therapy for hypertension? Systematic review and metanalyses. J Hypertens 2006; 24:2131-2141.

30. Dulin B, Abraham WT. Pharmacology of carvedilol. Am J Cardiol 2004; 93(9A):3B-6B.

31. Pedersen ME, Cockcroft JR. The vasodilatory betablockers. Curr Hypertens Rep 2007; 9(4):269-277.

32. De Cree J, Van Nueten L, Geukens H, Verhaegen H. Comparative cardiac haemodynamics of bisoprolol, celiprolol, carvedilol and nebivolol in normal volunteers. Int J Clin Pharmacol Res 1992; 12(4):159-163.

33. López-Sendón J, Swedberg K, McMurray J et al. Task Force on Beta-Blockers of the European Society of Cardiology. Expert consensus document on betaadrenergic receptor blockers. Eur Heart J 2004 Aug; 25(15):1341-1362. 
34. Doughty RN, White HD. Carvedilol: use in chronic heart failure. Expert Rev Cardiovasc Ther 2007 Jan; 5(1):21-31.

35. Hjalmarson A, Goldstein S, Fagerberg B et al. Effects of controlled-release metoprolol on total mortality, hospitalizations, and well-being in patients with heart failure: the Metoprolol CR/XL Randomized Intervention Trial in congestive heart failure (MERIT-HF). MERIT-HF Study Group. JAMA. 2000 Mar 8; 283(10):1295-1302.

36. Rosenberg J, Gustafsson F. Bisoprolol for congestive heart failure. Expert Opin Pharmacother 2008; 9(2):293-300.

37. Flather MD, Shibata MC, Coats AJ et al. SENIORS Investigators. Randomized trial to determine the effect of nebivolol on mortality and cardiovascular hospital admission in elderly patients with heart failure (SENIORS). Eur Heart J 2005; 26:215-225.

38. Celik T, Iyisoy A, Kursaklioglu H et al. Comparative effects of nebivolol and metoprolol on oxidative stress, insulin resistance, plasma adiponectin and soluble P-selectin levels in hypertensive patients. J Hypertens 2006; 24(3):591-596.

39. Doumas M, Tsakiris A, Douma S et al. Beneficial effects of switching from beta-blockers to nebivolol on the erectile function of hypertensive patients. Asian J Androl 2006; 8(2):177-182.

40. The ALLHAT Officers and Coordinators for the ALLHAT Collaborative Research Group. Major cardiovascular events in hypertensive patients randomized to doxazosin $v s$. chlorthalidone. The Antihypertensive and Lipid-Lowering Treatment to prevent Heart Attack Trial (ALLHAT). JAMA 2000; 283:1967-1975.

41. Lubsen J, Wagener G, Kirwan BA, de Brouwer S, Poole-Wilson PA; ACTION (A Coronary disease Trial Investigating Outcome with Nifedipine GITS) investigators. Effect of long-acting nifedipine on mortality and cardiovascular morbidity in patients with symptomatic stable angina and hypertension: the ACTION trial. J Hypertens 2005; 23(3):641-648.

42. White WB. Angiotensin-converting enzyme inhibitors in the treatment of hypertension: an update. J Clin Hypertens (Greenwich) 2007; 9(11):876-882.

43. Garg R, Yussuf S. Collaborative Group on ACEinhibitor Trials. Overview of randomized trials of angiotensin converting enzyme inhibitors on mortality and morbidity in patients with heart failure. JAMA 1995; 273:1450-1456.

44. Pfeffer MA. Angiotensin-converting enzyme inhibition in congestive heart failure: benefit and perspective. Am Heart J 1993 Sep; 126(3 Pt 2):789-793.

45. Flatcher MD, Yussuf S, Kober L et al. for the ACEInhibitor Myocardial Infarction Collaborative Group. Long term ACE-inhibitor therapy in patients with heart failure or left ventricular dysfunction: a systematic overview of data from individual patients. Lancet 2000; 355:1575-1581.

46. Palardy M, Ducharme A, O’Meara E. Inhibiting the renin-angiotensin system with ACE inhibitors or ARBs after MI. Curr Heart Fail Rep 2007; 4(4):190-197.

47. Fox KM, Henderson JR, Bertrand ME, Ferrari R, Remme WJ, Simoons ML. The European trial on reduction of cardiac events with perindopril in stable coronary artery disease (EUROPA). Eur Heart J 1998 Sep; 19 Suppl J:J52-55.

48. Lewis EJ, Hunsicker LG, Bain RP, Rohde RD. The effect of angiotensin-converting-enzyme inhibition on diabetic nephropathy. The Collaborative Study Group. N Engl J Med 1993; 329:1456-1462.

49. Maschio G, Alberti D, Janin G et al. Effect of the angiotensin-converting-enzyme inhibitor benazepril on the progression of chronic renal insufficiency. The Angiotensin-Converting-Enzyme Inhibition in Progressive Renal Insufficiency Study Group. N Engl J Med 1996; 334(15):939-945.

50. Giatra I, Lau J, Levey AS. Effect of angiotensinconverting enzyme inhibitors on the progression of non-diabetic renal disease: a meta-analysis of randomized trials. Ann Intern Med 1997; 127:337-345.

51. Bakris GL, Weir MR. Angiotensin-converting enzyme inhibitor-associated elevations in serum creatinine: is this a cause for concern? Arch Intern Med 2000 Mar $13 ; 160(5): 685-693$.

52. Cohn JN, Tognoni G on behalf of Valsartan Heart Failure Trial Investigators. A randomized trial of the angiotensin receptor blocker valsartan in chronic heart failure. N Engl J Med 2001; 345:167-175.

53. Pfeffer MA, Swedberg K, Granger CB et al. CHARM Investigators and Committees. Effects of candesartan on mortality and morbidity in patients with chronic heart failure: The CHARM-Overall Program. Lancet 2003; 362 (9386):759-766.

54. Konstam MA, Neaton JD, Dickstein K et al. HEAAL Investigators. Effects of high-dose versus low-dose losartan on clinical outcomes in patients with heart failure (HEAAL study): a randomised, double-blind trial. Lancet 2009; 374(9704):1840-1848.

55. Papademetriou V, Farsang C, Elmfeldt D et al. for the SCOPE study group. Stroke prevention with the angiotensin II type-1 receptor blocker candesartan in elderly patients with isolated systolic hypertension. The Study on Cognition and Prognosis in Elderly (SCOPE). J Am Coll Cardiol 2004; 44:1175-1180.

56. Schrader J, Luders S, Kulschewsky A et al., The ACCESS Study, Evaluation of acute candesartan cilexetil therapy in stroke survivors. Stroke 2003; 34:1699-1703.

57. Brenner BM, Cooper ME, Zeeuw D et al. Effects of losartan on renal and cardiovascular outcomes in patients with type 2 diabetes and nephropathy. N Engl J Med 2001; 345:861-869.

58. Lewis EJ, Hunsicker LG, Clarke WR. Renoprotective effect of the angiotensin receptor antagonist irbersartan in patients with nephropathy due to type 2 diabetes. $\mathrm{N}$ Eng J Med 2001; 345:851-860.

59. Mann JF, Schmieder RE, McQueen $M$ et al. ONTARGET investigators. Renal outcomes with telmisartan, ramipril, or both, in people at high vascular risk (the ONTARGET study): a multicentre, randomised, double-blind, controlled trial. Lancet 2008; 372(9638):547-553.

60. Parving $\mathrm{H}-\mathrm{H}$, Lehnert $\mathrm{H}$, Brochner-Mortensen J, Gomis R, Andersen S, Arner P. The effect of irbersartan on the development of diabetic nephropathy in patients with type 2 diabetes. $N$ Engl J Med 2001; 345:870-878. 
61. Reboldi G, Angeli F, Cavallini C, Gentile G, Mancia G, Verdecchia P. Comparison between angiotensinconverting enzyme inhibitors and angiotensin receptor blockers on the risk of myocardial infarction, stroke and death: a meta-analysis. J Hypertens 2008; 26(7):1282-1289.

62. Strauss MH, Lonn EM, Verma S. Is the jury out? Class specific differences on coronary outcomes with ACE-Inhibitors and ARBs: Insight from meta-analysis and the Blood Pressure Lowering Treatment Trialist Collaboration. Eur Heart J 2005; 26:2351-2353.

63. Cheung BM, Cheung GT, Lauder IJ, Lau CP, Kumana CR. Meta-analysis of large outcome trials of angiotensin receptor blockers in hypertension. J Hum Hypertens 2006; 20:37-43.

64. Abuissa H, Jones PG, Marso SP, O’Keefe JH Jr. Angiotensin-converting enzyme inhibitors or angiotensin receptor blockers for prevention of type 2 diabetes: a meta-analysis of randomized clinical trials. J Am Coll Cardiol 2005; 46:821-826.

65. Lindholm LH, Persson M, Alaupovic P, Carlberg B, Svensson A, Samuelsson O. Metabolic outcome during 1 year in newly detected hypertensives: results of the Antihypertensive Treatment and Lipid Profile in a North of Sweden Efficacy Evaluation (ALPINE study). J Hypertens 2003; 21:1563- 1574.

66. Wuerzner G, Azizi M. Renin inhibition with aliskiren. Clin Exp Pharmacol Physiol 2008; 35(4): 426-430.

67. Müller DN, Derer W, Dechend R. Aliskiren-mode of action and preclinical data. J Mol Med 2008; 86(6):659-662.

68. Krop M, Garrelds IM, de Bruin RJ et al. Aliskiren accumulates in renin secretory granules and binds plasma prorenin. Hypertension 2008; 52(6): 1076-1083.

69. Danser AH. (Pro)renin receptors: are they biologically relevant? Curr Opin Nephrol Hypertens 2009; 18(1):74-78.

70. Singh VP, Le B, Khode R, Baker KM, Kumar R. Intracellular angiotensin II production in diabetic rats is correlated with cardiomyocyte apoptosis, oxidative stress, and cardiac fibrosis. Diabetes 2008 Dec; 57(12):3297-3306.

71. Sakoda M, Ichihara A, Kurauchi-Mito A et al. Aliskiren inhibits intracellular angiotensin II levels without affecting (pro)renin receptor signals in human podocytes. Am J Hypertens 2010; 23(5):575-580.

72. Musini VM, Fortin PM, Bassett K, Wright JM. Blood pressure lowering efficacy of renin inhibitors for primary hypertension. Cochrane Database Syst Rev. 2008; 8;(4):CD007066.

73. Musini VM, Fortin PM, Bassett K, Wright JM. Blood pressure lowering efficacy of renin inhibitors for primary hypertension: a Cochrane systematic review. J Hum Hypertens 2009; 23(8):495-502.

74. Luft FC, Weinberger MH. Antihypertensive therapy with aliskiren. Kidney Int 2008; 73(6):679-683.

75. Pimenta E, Oparil S. Role of aliskiren in cardiorenal protection and use in hypertensives with multiple risk factors. Vasc Health Risk Manag 2009; 5(1):453-463.

76. Solomon SD, Appelbaum E, Manning WJ et al. Aliskiren in Left Ventricular Hypertrophy (ALLAY)
Trial Investigators. Effect of the direct renin inhibitor aliskiren, the angiotensin receptor blocker losartan, or both on left ventricular mass in patients with hypertension and left ventricular hypertrophy. Circulation 2009 Feb 3; 119(4):530-537.

77. Parving HH, Persson F, Lewis JB, Lewis EJ, Hollenberg NK; AVOID Study Investigators. Aliskiren combined with losartan in type 2 diabetes and nephropathy. $\mathrm{N}$ Engl J Med 2008 5; 358(23):2433-2446.

78. Reappraisal of European Guidelines on hypertension management: a European Society of hypertension task force document. J Hypertens 2009; 27:2121-2158.

79. Hansson L, Zanchetti A, Carruthers SG et al. Effects of intensive blood-pressure lowering and low-dose aspirin in patients with hypertension: principal results of the Hypertension Optimal Treatment (HOT) randomized trial. Lancet 1998 ; 351:1755-1762.

80. UK Prospective Diabetes Study Group. Tight blood pressure control and the risk of macrovascular and microvascular complications in type diabetes. UKPDS 38. BMJ 1998; 317:703-713.

81. American Diabetes Association. Standards of Medical Care in Diabetes 2010. Diabetes Care 2010, 33 (suppl 1):S1-S61.

82. Petterson JC, Adler S, Bukart JM et al. Blood pressure control, proteinuria, and the progression of renal disease. The Modification of Diet in Renal Disease Study (MDRD). Ann Intern Med 1995; 123:754-762.

83. Du X, Cruickshank K, McNamee R et al. CaseControl of stroke and quality of hypertension control in north west England. BMJ 1997; 341:272-276.

84. Jamerson K, Weber MA, Bakris GL et al. Benazepril plus amlodipine or hydrochlorothiazide for hypertension in high-risk patients. N Engl J Med 2008; 359(23):2417-2428.

85. Bakris GL, Sarafi PA, Weir MR et al. for the ACCOMPLISH Trial investigators. Renal outcomes with different fixed-dose combination therapies in patients with hypertension at high risk for cardiovascular events (ACCOMPLISH): a pre-specified secondary analysis of a randomised controlled trial. Lancet 2010; 375(9721):1173-1181.

86. MacKinnon M, Shurraw S, Akbari A, Knoll GA, Jaffey J, Clark HD. Combination therapy with an angiotensin receptor blocker and an ACE inhibitor in proteinuric renal disease: a systematic review of the efficacy and safety data. Am J Kidney Dis 2006; 48(1):8-20.

87. Kunz R, Friedrich C, Wolbers M, Mann J F. Metaanalysis: effect of monotherapy and combination therapy with inhibitors of the renin angiotensin system on proteinuria in renal disease. Ann Intern Med 2008; 148(1):30-48.

88. Pimenta E, Gaddam KK, Oparil S. Mechanisms and treatment of resistant hypertension. J Clin Hypertens (Greenwich). 2008; 10(3):239-244.

89. Antithrombotic Trialists' (ATT) Collaboration, Baigent C, Blackwell L, Collins R et al. Aspirin in the primary and secondary prevention of vascular disease: collaborative meta-analysis of individual participant data from randomised trials. Lancet 2009; 373(9678):1849-1860. 
90. Busnello RG, Melchior R, Faccin C et al. Características associadas ao abandono do acompanhamento de pacientes hipertensos atendidos em um ambulatório de referência. Arq Bras Cardiol 2001; 76:349-351.

91. Pierin AMG, Mion Jr D, Fukushima J, Pinto AR, Kaminaga M. O perfil de um grupo de pessoas hipertensas de acordo com conhecimento e gravidade da doença. In: Rev Esc Enf USP 2001; 35:11-18.

92. Lessa I, Fonseca J. Raça, aderência ao tratamento e/ ou consultas e controle da hipertensão arterial. Arq Bras Cardiol, 1997; 68:443-449.

93. Strelec MAM, Pierin AMG, Mion Jr D. A influência do conhecimento sobre a doenças e atitude frente a tomada dos remédios no controle da hipertensão arterial. Arq Bras Cardiol 2003; 81:349-354.

94. Gus I, Harzheim E, Zaslavsky C, Medina C, Gus M. Prevalência, reconhecimento e controle da hipertensão arterial sistêmica no Estado do Rio Grande do Sul. Arq Bras Cardiol 2004; 83(5):424-428.

95. Pierin AMG, Strelec MAAM, Mion Jr. D. O desafio do controle da hipertensão arterial e a adesão ao tratamento. In: Pierin AMG. Hipertensão arterial: uma proposta para o cuidar. São Paulo: Ed. Manole, 2004; p. 275-289.
96. Vicek M, Bur A, Woisetschläger C, Herkner H, Laggner AN, Hirschl MM. Association between hypertensive urgencies and subsequent cardiovascular events in patients with hypertension. J Hypertens 2008; 26:657-662.

97. Dib MW, Riera R, Ferraz MB. Estimate of the anual cost of arterial hypertension treatment in Brazil Pan American Journal of Public Health 2010 (in press).

98. WHO Technical Report Series, no. 628, 1978 (Arterial hypertension: report of a WHO Expert Committee, p. 9).

99. Disponível em: http://educacao.cardiol.br/coracoesdobrasil. Acessado em 25 de Maio de 2009.

100. Moreira GC, Cipullo J P Martin JF, et al. Evaluation of the awareness, control and cost-effectiveness of hypertension treatment in a Brazilian city: populational study. J Hypertens 2009; 27:1900-1907. 